\title{
LVRT Strategy -based Multi-controller Switching for DFIG
}

\author{
Shi-Hong $\mathrm{GAO}^{1,2, \mathrm{a}}$, Cheng-Xiong $\mathrm{MAO}^{1, \mathrm{~b},{ }^{*},}$, Dan WANG ${ }^{1, \mathrm{c}}$
}

\author{
'State Key Laboratory of Advanced Electromagnetic Engineering and Technology, Huazhong \\ University of Science and Technology, Wuhan, China \\ ${ }^{2}$ School of Information Engineering, Hubei University for Nationalities, Enshi, China \\ agaosh0708@163.com, bcxmao@mail.hust.edu.cn, 'wangdan@mail.hust.edu.cn \\ ${ }^{*}$ Corresponding author
}

\begin{abstract}
Keywords: Doubly-fed induction generation (DFIG), Low voltage ride-through (LVRT), PI controller, Four-level hysteresis current controller (FLHCC), Rotor-side converter (RSC).

Abstract. The RSC is generally controlled by using PI controller, but its narrow bandwidth and slow transient response speed limit the LVRT capability of DFIG. So, a LVRT strategy-based multi-controller switching is proposed in this paper. According to different rotor current setting value, the corresponding control strategy of RSC is implemented. That is, the PI controller is used during normal PCC voltage. However, during PCC voltage sag, the control strategy is switched to FLHCC when the rotor current reaches the first setting value, and a set of resistors is connected into the rotor circuit when the rotor current reaches the second setting value. In addition, the FLHCC implementation, the control strategy switching and the series resistance determination are also introduced in detail. Finally, the feasibility of the proposed LVRT strategy is verified by the dynamic simulation.
\end{abstract}

\section{Introduction}

With the continuous progress of wind power generation technology, the variable speed constant frequency (VSCF) wind power generation has become the mainstream, in which the DFIGs are most used in wind power generation system, because of its unique mode of integration into the grid. But it is highly sensitive to the grid disturbance, e.g., grid fault [1]. It will result in the voltage dip of the point of common coupling (PCC), and the result is to cause the rotor overcurrent of DFIG. If the rotor overcurrent is not controlled by taking certain measures, the RSC is extremely easy to be damaged because of over-heat effect caused by the rotor overcurrent [2]. It makes the DFIG disconnect with grid, and this will have a serious impact on the safety and stability of the grid operation. Therefore, how to improve the LVRT capability of DFIG is a subject worthy of further study. Through referring a large number of literatures on this issue, the main research findings in recent years are as follows: (1) Adding some hardware facilities, such as the rotor crowbar circuit [3], the dc-link energy absorption or storage circuit [4], and the voltage compensator or impedance network of stator side or the series resistor of rotor side [5-7]. The above methods can greatly improve the LVRT capability of DFIG, but increase the cost of DFIG system and the complexity of control system to some extent; (2) Improving on conventional control strategies, such as the improved PI control strategy and the transient stator flux weakening method [8-9], which means do not increase the hardware cost of DFIG system. But the transient control performance becomes worse during the PCC voltage dip, and as a result that greatly limits the LVRT capability of DFIG.

Compared with the conventional PI controller, the hysteresis current controller (HCC) has an excellent transient performance, such as the fast transient response speed and strong control robustness. It is often used in an active power filter of power system to reduce or even eliminate the grid harmonic components that are mainly caused by switching operation and nonlinear loads.

Combining excellent steady control performance of PI controller and quick transient response speed of HCC, an improved control strategy in this paper is proposed to improve the LVRT capability of DFIG. The main idea is that the RSC control uses the PI controller during normal PCC voltage, and during the PCC voltage dip, according to the different setting limits of rotor current, a set of resistors is connected into the rotor circuit to limit the initial rotor overcurrent and the 
FLHCC is used to rapidly track the rotor command current. After the PCC voltage restores to normal, the PI controller is again used to control the RSC. Therefore, this hybrid control strategy considers the steady performance of DFIG and its transient performance as well.

\section{Transient Characteristics of Rotor Voltage and Current during PCC Voltage Dip}

For easy to write the dynamic voltage and flux linkage equations of DFIG, the reference directions of voltage, current and flux linkage adopt the motor convention in this paper. Thus, the dynamic equations of voltage and flux linkage vector in an arbitrary reference coordinate can be written out $[1,4,9]$, in which the rotor-side parameters have been converted to the stator side. These equations are given as follows:

$$
\left\{\begin{array}{l}
\boldsymbol{v}_{\mathrm{s}}=R_{\mathrm{s}} \boldsymbol{i}_{\mathrm{s}}+p \boldsymbol{\psi}_{\mathrm{s}}+j \omega \boldsymbol{\psi}_{\mathrm{s}} \quad ; \quad \boldsymbol{v}_{\mathrm{r}}=R_{\mathrm{r}} \boldsymbol{i}_{\mathrm{r}}+p \boldsymbol{\psi}_{\mathrm{r}}+j\left(\omega-\omega_{\mathrm{r}}\right) \boldsymbol{\psi}_{\mathrm{r}} \\
\boldsymbol{\psi}_{\mathrm{s}}=L_{\mathrm{s}} \boldsymbol{i}_{\mathrm{s}}+L_{\mathrm{m}} \boldsymbol{i}_{\mathrm{r}} \quad ; \quad \boldsymbol{\psi}_{\mathrm{r}}=L_{\mathrm{m}} \boldsymbol{i}_{\mathrm{s}}+L_{\mathrm{r}} \boldsymbol{i}_{\mathrm{r}}
\end{array}\right.
$$

where $\boldsymbol{v}, \boldsymbol{i}, \boldsymbol{\psi}$ are voltage, current and flux linkage vectors, respectively; $R, L$ are resistance and self-inductance, respectively; $s, r, m$ subscripts denote parameters of the stator, rotor windings and excitation, respectively; $\omega$ is angular speed of reference frame; $p$ denotes the differential operator, which has $p=d / d t$.

Selecting stator flux linkage and rotor current as state variables, and eliminating the stator current and rotor flux linkage from Eq.(1), the relationship between rotor voltage and state variables can be derived as follows:

$$
\boldsymbol{v}_{\mathrm{r}}=k_{\mathrm{s}}\left[p+j\left(\omega-\omega_{\mathrm{r}}\right)\right] \boldsymbol{\psi}_{\mathrm{s}}+\left\{R_{\mathrm{r}}+\sigma L_{\mathrm{r}}\left[p+j\left(\omega-\omega_{\mathrm{r}}\right)\right]\right\} \boldsymbol{i}_{\mathrm{r}}=\boldsymbol{v}_{\mathrm{r} 0}+\left\{R_{\mathrm{r}}+\sigma L_{\mathrm{r}}\left[p+j\left(\omega-\omega_{\mathrm{r}}\right)\right]\right\} \boldsymbol{i}_{\mathrm{r}}
$$

where $\boldsymbol{v}_{\mathrm{r} 0}$ denotes rotor open-circuit voltage generated by the stator dynamic flux linkage, which has $\boldsymbol{v}_{\mathrm{r} 0}=k_{\mathrm{s}}\left[p+j\left(\omega-\omega_{\mathrm{r}}\right)\right] ; k_{\mathrm{s}}$ is defined as the coupling effect coefficient of DFIG stator winding, which has $k_{\mathrm{s}}=L_{\mathrm{m}} / L_{\mathrm{s}} ; \sigma$ is called as the leakage coefficient of DFIG rotor windings, which has $\sigma=1-L_{\mathrm{m}}^{2} /\left(L_{\mathrm{s}} L_{\mathrm{r}}\right)$.

\subsection{Symmetrical Dip Case of PCC Voltage}

If three-phase short circuit fault occurs in the grid, it will lead to symmetrical PCC voltage dip. Assuming that the voltage amplitude drops from $V_{\mathrm{s}}$ to $(1-k) V_{\mathrm{s}}$, according to the conservation principle of flux linkage, and neglecting the DFIG stator winding resistance, the stator flux linkage vector in the stator reference coordinate can be derived from Eq.(1), it can be expressed as

$$
\boldsymbol{\psi}_{\mathrm{s}}=\boldsymbol{\psi}_{\mathrm{sf}}+\boldsymbol{\psi}_{\mathrm{sn}}=(1-k) V_{\mathrm{s}} e^{j \omega_{1} t} / j \omega_{1}+k V_{\mathrm{s}} e^{-t / \tau_{\mathrm{s}}} / j \omega_{1}
$$

where $\boldsymbol{\psi}_{\mathrm{sf}}, \boldsymbol{\psi}_{\mathrm{sn}}$ are steady and transient components of the stator flux linkage vector, respectively; $k$ denotes the voltage dip degree coefficient; $\tau_{\mathrm{s}}$ is the stator winding time constant, which has $\tau_{\mathrm{s}}=L_{\mathrm{s}} / R_{\mathrm{s}} ; \omega_{1}$ is the synchronous angular speed of the grid.

In terms of Eqs.(2) and (3), the rotor voltage vector $\boldsymbol{v}_{\mathrm{r}}$ in the rotor reference coordinate can be obtained as follows:

$$
\boldsymbol{v}_{\mathrm{r}}=k_{\mathrm{s}} V_{\mathrm{s}}\left[s(1-k) e^{j s \omega_{1} t}-k\left(j \omega_{\mathrm{r}}+1 / \tau_{\mathrm{s}}\right) e^{-j(1-s) \omega_{1} t} e^{-t / \tau_{\mathrm{s}}}\right]+\left(R_{\mathrm{r}}+\sigma L_{\mathrm{r}} p\right) \boldsymbol{i}_{\mathrm{r}}
$$

where $s$ is slip ratio of DFIG, which has $s=1-\omega_{\mathrm{r}} / \omega_{1}$.

Considering that the DFIG stator winding resistance $R_{\mathrm{s}}$ is very small, the influence of $1 / \tau_{\mathrm{s}}$ on the rotor voltage $v_{\text {r }}$ can be neglected. Therefore, the Eq.(4) can be simplified as

$$
\boldsymbol{v}_{\mathrm{r}}=k_{\mathrm{s}} V_{\mathrm{s}}\left[s(1-k) e^{j s \omega_{1} t}-(1-s) k e^{-j(1-s) \omega_{1} t} e^{-t / \tau_{\mathrm{s}}}\right]+\left(R_{\mathrm{r}}+\sigma L_{\mathrm{r}} p\right) \boldsymbol{i}_{\mathrm{r}}
$$

Before the PCC voltage drops, the rotor excitation voltage of DFIG is supplied by the RSC, it can be expressed as 


$$
v_{\mathrm{r}}=V_{\mathrm{r}} e^{j s \omega_{1} t}
$$

where $V_{r}$ is the amplitude of the rotor exciting voltage.

In order to simplify the theoretical analysis, the excitation voltage $\boldsymbol{v}_{\mathrm{r}}$ remains constant before and after the PCC voltage dip. The rotor current vector can be obtained from Eqs.(5) and (6), it can be described as

$$
\boldsymbol{i}_{\mathrm{r}}=\left\{\left[V_{\mathrm{r}}-k_{\mathrm{s}} V_{\mathrm{s}} s(1-k)\right] e^{j s \omega_{1} t}+k_{\mathrm{s}} V_{\mathrm{s}}(1-s) k e^{-j(1-s) \omega_{1} t} e^{-t / \tau_{\mathrm{s}}}\right\} /\left(R_{\mathrm{r}}+\sigma L_{\mathrm{r}} p\right)
$$

According to the Laplace and its inverse transform, an rotor current vector expression can be derived from Eq.(7). It consists of three current components: the transient component $\boldsymbol{i}_{\mathrm{rdc}}$ decaying by the time constant $\tau_{\mathrm{r}}$ that has $\tau_{\mathrm{r}}=\sigma L_{\mathrm{r}} / R_{\mathrm{r}}$, the periodic component $\boldsymbol{i}_{\mathrm{rn}}$ with the frequency (1s) $\omega_{1}$ and decaying by the time constant $\tau_{s}$, and the steady component with the frequency $s \omega_{1}$.

\subsection{Asymmetrical Dip Case of PCC Voltage}

If asymmetrical short circuit fault occurs in the grid, e.g., single-phase grounding or two-phase short circuit, it will cause the asymmetrical PCC voltage dip. According to the symmetrical component theory, the PCC voltage can be decomposed into positive, negative and zero sequence components [10], it can be expressed as

$$
\boldsymbol{v}_{\mathrm{s}}=\dot{V}_{\mathrm{s} 1} e^{j \omega_{1} t}+\dot{V}_{\mathrm{s} 2} e^{-j \omega_{1} t}+\dot{V}_{\mathrm{s} 0}
$$

where $\dot{V}_{\mathrm{s} 1}, \dot{V}_{\mathrm{s} 2}, \dot{V}_{\mathrm{s} 0}$ are the positive, negative and zero sequence voltage phasors.

In the above voltage components, only the positive and negative sequence voltage components establish the air gap flux linkage of DFIG. The sum of them constitutes the steady component of air gap flux linkage, but the zero sequence voltage component creates no air gap flux linkage. In terms of the conservation principle of flux linkage and ignoring $1 / \tau_{\mathrm{s}}$, the rotor open circuit voltage $\boldsymbol{v}_{\mathrm{r} 0}$ generated by the stator flux linkage $\boldsymbol{\psi}_{\mathrm{s}}$ similarly can be derived, it can be expressed as

$$
\boldsymbol{v}_{\mathrm{r} 0}=\boldsymbol{v}_{\mathrm{r} 1}+\boldsymbol{v}_{\mathrm{r} 2}+\boldsymbol{v}_{\mathrm{rn}}=k_{s}\left[s V_{\mathrm{s} 1} e^{j s \omega_{1} t}-(2-s) V_{\mathrm{s} 2} e^{-j(2-s) \omega_{1} t}-j(1-s) \omega_{1} \psi_{\mathrm{n} 0} e^{-j(1-s) \omega_{1} t} e^{-t / \tau_{\mathrm{s}}}\right]
$$

where $\boldsymbol{v}_{\mathrm{r} 1}, \boldsymbol{v}_{\mathrm{r} 2}$ are the positive and negative sequence steady component of rotor open-circuit voltage; $\boldsymbol{v}_{\text {rn }}$ is the transient component of rotor open-circuit voltage; $\psi_{\mathrm{n} 0}$ is the initial value of the stator flux linkage transient component.

Typical asymmetrical grid faults have single-phase grounding fault and two-phase short circuit fault. They will lead to asymmetrical PCC voltage dip. The positive, negative and zero sequence voltage components are shown in Tab.1.

Tab.1 Voltage sequence component

\begin{tabular}{l|c|c|c}
\hline fault types & $V_{\mathrm{s} 1}$ & $V_{\mathrm{s} 2}$ & $V_{\mathrm{s} 0}$ \\
\hline phase a voltage dip & $(1-k / 3) V_{\mathrm{s}}$ & $-k V_{\mathrm{s}} / 3$ & $-k V_{\mathrm{s}} / 3$ \\
\hline phases b and c voltage dip & $(1-k / 2) V_{\mathrm{s}}$ & $k V_{\mathrm{s}} / 2$ & $k V_{\mathrm{s}} / 2$ \\
\hline
\end{tabular}

Combining Eqs.(2), (6) and (9), the rotor current vector expression similarly can be derived, and it consists of four current components: the transient component $\boldsymbol{i}_{\text {rdc }}$ decaying by the time constant $\tau_{\mathrm{r}}$, the positive sequence steady component $\boldsymbol{i}_{\mathrm{rf} 1}$ with the frequency $s \omega_{1}$, the negative sequence steady component $\boldsymbol{i}_{\text {rf2 }}$ with the frequency $(2-s) \omega_{1}$, and the periodic component $\boldsymbol{i}_{\text {rn }}$ with the frequency $(1-s) \omega_{1}$ and decaying by the time constant $\tau_{\mathrm{s}}$.

\subsection{Rotor Current Dynamic Waveforms}

In the previous chapter, the rotor current dynamic characteristics during the PCC voltage dip are analyzed in detail. In the following, to verify the correctness of the above theoretical analysis, the dynamic simulations of rotor current are carried out for different voltage dip types. The main DFIG parameters used in the dynamic simulation are shown in the Tab.A1 of the appendix. In this paper, 
the case of the PCC voltage dip degree coefficient $k=1$ is only studied. The RSC is still connected with the DFIG rotor circuit during the PCC voltage dip, and the control strategy of RSC adopts the stator flux vector orientation. For different PCC voltage dip types, the phase a rotor current dynamic waveforms are shown in Fig.1.

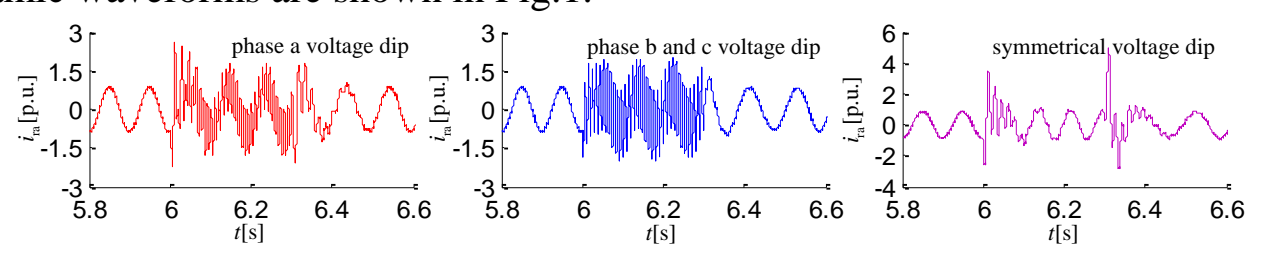

Fig.1 Phase a rotor current dynamic waveforms

It can be seen from Fig.1 that, during the symmetrical voltage dip, the rotor circuit flows through very large overcurrent that exists at the moment of voltage sag and recovery. But during the asymmetrical voltage dip, a larger rotor oscillation current lasts throughout the voltage sag.

\section{Proposed FLHCC}

\subsection{Principle of $\mathrm{HCC}$}

Detailed HCC principle analysis is introduced in [11] and [12]. In the stationary $\alpha-\beta$ reference coordinate, eight discrete space voltage vectors of RSC output can be expressed as [13]

$$
\begin{cases}\boldsymbol{v}_{\mathrm{r}}=2 V_{\mathrm{dc}} e^{j(k-1) \pi / 3} / 3 & k=1,2, \cdots 6 \\ \boldsymbol{v}_{\mathrm{r}}=0 & k=0,7\end{cases}
$$

If the rotor resistance is neglected, the error equation of rotor current in the rotor reference coordinate can be derived from Eq. (2), it can be described as

$$
\sigma L_{\mathrm{r}} p \Delta \boldsymbol{i}_{\mathrm{r}}=\boldsymbol{v}_{\mathrm{r}}^{*}-\boldsymbol{v}_{\mathrm{r}}
$$

where $\Delta \boldsymbol{i}_{\mathrm{r}}$ is the current error that has $\Delta \boldsymbol{i}_{\mathrm{r}}=\boldsymbol{i}_{\mathrm{r}}^{*}-\boldsymbol{i}_{\mathrm{r}}$, in which $\boldsymbol{i}_{\mathrm{r}}^{*}$ is the rotor command current; $\boldsymbol{v}_{\mathrm{r}}^{*}$ is the rotor command voltage, which has $\boldsymbol{v}_{\mathrm{r}}^{*}=\boldsymbol{v}_{\mathrm{r} 0}+\sigma L_{\mathrm{r}} p \boldsymbol{i}_{\mathrm{r}}^{*}$.

In terms of Eq.(11), the rotor command voltage $\boldsymbol{v}_{\mathrm{r}}^{*}$ must be accurately determined to satisfy the rotor current error $\Delta \boldsymbol{i}_{\mathrm{r}}=0$. So, it requires that the rotor open-circuit voltage $\boldsymbol{v}_{\mathrm{r} 0}$ and the rotor command current derivative $p \boldsymbol{i}_{\mathrm{r}}^{*}$ are accurately measured, but this is difficult to achieve in actual engineering.

\subsection{Proposed FLHCC}

The structure of FLHCC in the stationary $\alpha-\beta$ reference coordinate is shown in Fig.2, in which the bandwidth of two HCCs is $\delta+\Delta \delta$.
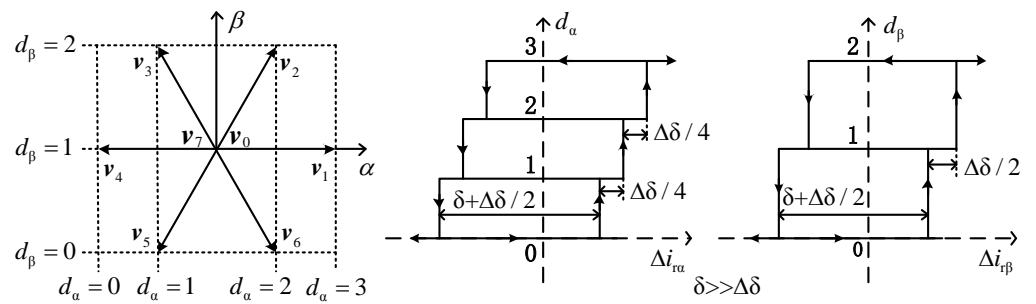

Fig.2 Structure of FLHCC

The FLHCC proposed in this paper canceled the outer loop of the double HCC introduced in [11], in which the outer loop is used to detect the command voltage section. Furthermore, the FLHCC solved the judgment of the RSC output voltage uncertainty presented in [12]. The spatial position of the command voltage vector of FLHCC is automatically determined and updated by two HCCs. According to the status values $d_{\alpha} d_{\beta}$ of two HCCs, the optimum voltage vector of RSC output is 
directly obtained by querying the switch table, and the pulse width modulation (PWM) unit is eliminated. Therefore, the FLHCC has a very fast transient response tracking speed.

The switch table of FLHCC can be derived from Fig.2, and it is shown in Tab.2.

Tab.2 Switch table of LFHCC

\begin{tabular}{cccc||cccc}
\hline$d_{\alpha}$ & & $d_{\beta}$ & & \multicolumn{3}{c}{$d_{\beta}$} \\
& 0 & 1 & 2 & $d_{\alpha}$ & 0 & 1 & 2 \\
\hline 0 & $\boldsymbol{v}_{5}$ & $\boldsymbol{v}_{4}$ & $\boldsymbol{v}_{3}$ & 2 & $\boldsymbol{v}_{6}$ & $\left.\boldsymbol{v}_{0}\right|_{\boldsymbol{v}_{1}, \boldsymbol{v}_{3}, \boldsymbol{v}_{5}} ;\left.\boldsymbol{v}_{7}\right|_{\boldsymbol{v}_{2}, \boldsymbol{v}_{4}, \boldsymbol{v}_{6}}$ & $\boldsymbol{v}_{2}$ \\
1 & $\boldsymbol{v}_{5}$ & $\left.\boldsymbol{v}_{0}\right|_{\boldsymbol{v}_{1}, \boldsymbol{v}_{3}, \boldsymbol{v}_{5}} ;\left.\boldsymbol{v}_{7}\right|_{\boldsymbol{v}_{2}, \boldsymbol{v}_{4}, \boldsymbol{v}_{6}}$ & $\boldsymbol{v}_{3}$ & 3 & $\boldsymbol{v}_{6}$ & $\boldsymbol{v}_{1}$ & $\boldsymbol{v}_{2}$ \\
\hline
\end{tabular}

In order to reduce the switch frequency of RSC, it is very necessary to properly introduce zero voltage vectors. It can be seen from Tab.3 that the selection logic of zero voltage vectors $\boldsymbol{v}_{0}\left(\boldsymbol{v}_{7}\right)$ is $S_{\mathrm{a}} S_{\mathrm{b}}+S_{\mathrm{b}} S_{\mathrm{c}}+S_{\mathrm{c}} S_{\mathrm{a}}$. The principle diagram of FLHCC is shown in Fig.3.

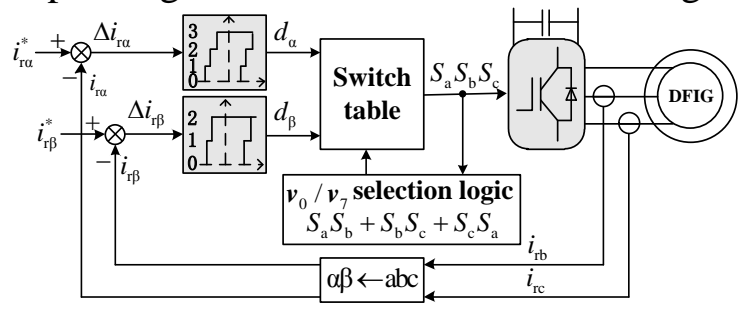

Fig.3 Principle diagram of FLHCC

\section{Proposed LVRT Control Strategy}

Combining the superior steady performance of PI controller and the fast transient response speed of FLHCC, a LVRT control strategy-based multi- controller switching is proposed in this paper. When the PCC voltage is normal, the PI controller is used to satisfy the steady performance of rotor current. During the PCC voltage sag, the control strategy of RSC is switched to the FLHCC that it ensures the fast transient tracking performance of rotor current. In addition, in the moment of PCC voltage fall and recovery, a set of resistors that acts as the roles of the current limiter and voltage divider over the overcurrent and overvoltage are connected into the DFIG rotor circuit. This purpose is to make sure the RSC doesn't run out of control.

\subsection{Resistance Determination of Series Resistor}

It can be seen from Fig. 1 that a very high rotor current is induced in the moment of PCC voltage fall and recovery. Therefore, the resistance determination basis of series resistor is that the PCC voltage symmetrically drops to zero. Namely, the PCC voltage dip degree coefficient $k=1$. The maximum amplitude of rotor current can be derived from Eq.(7), it can be expressed as

$$
i_{\mathrm{rmax}}=i_{\mathrm{ra}}\left(0_{-}\right)+\frac{k_{\mathrm{s}}(1-s) V_{\mathrm{s}} \tau}{\sigma L_{\mathrm{r}} \sqrt{1+\left(\omega_{\mathrm{r}} \tau\right)^{2}}}\left[1-\frac{1}{\sqrt{1+\left(\omega_{\mathrm{r}} \tau\right)^{2}}}\right]+\frac{V_{\mathrm{r}}}{\sigma L_{\mathrm{r}}} \frac{\tau_{\mathrm{r}}}{\sqrt{1+\left(\omega_{\mathrm{r}} \tau_{\mathrm{r}}\right)^{2}}}
$$

where $i_{\mathrm{ra}}\left(0_{-}\right)$is the phase a rotor current of the moment before the PCC voltage sags; $\tau_{\mathrm{r}}$ is the rotor winding time constant with considering the series resistor, which has $\tau_{\mathrm{r}}=\sigma L_{\mathrm{r}} /\left(R_{\mathrm{r}}+R_{\mathrm{SR}}\right) ; \tau$ is a composite time constant, which has $\tau=\tau_{\mathrm{r}} /\left(\tau_{\mathrm{s}}-\tau_{\mathrm{r}}\right)$.

Then, according to the safety limits of rotor current and voltage $I_{r_{-} l i m}$ and $V_{r_{-} \text {lim }}$, and combining the time constant $\tau_{\mathrm{r}}$, the resistance of series resistor can be calculated.

\subsection{Controller Switching Strategy}

When the PCC voltage is normal, the PI controller is used to adjust the rotor current. But during the PCC voltage dip, according to the setting rotor current $I_{\text {th_FLHCC, }}$, the PCC voltage monitoring unit activates the FLHCC. If the rotor current continues to rise and reaches the setting rotor current 
$I_{\text {th_SR }}$, a set of resistors is connected into the rotor circuit, and is removed until the rotor current is less than the setting value $I_{\text {th_SR }}$. After simulation analysis, the current limit $I_{\text {th_FLHCC }}$ is 1.25 p.u. to not trigger the FLHCC under moderate voltage dip. The other one $I_{\text {th_SR }}$ is 1.5 p.u. to not frequently activate the series resistor under deep voltage dip. The controller switching strategy proposed in this paper is shown in Fig.4.

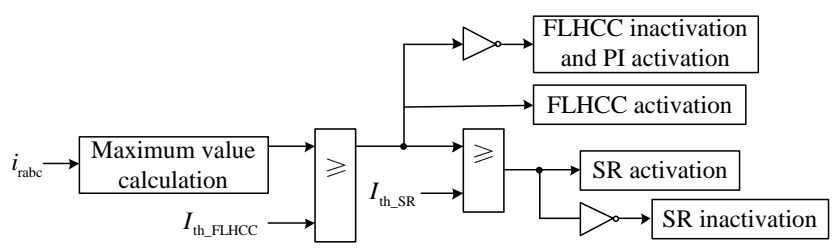

Fig.4 Controller switching strategy

\subsection{Dynamic Simulation Research}

To validate the feasibility of the LVRT proposed in this paper, a dynamic simulation model is constructed in Simulink platform, in which the main DFIG parameters are shown in Tab.A1 of the appendix. In the process of dynamic simulation, the power and speed of DFIG are kept constant. The schematic diagram of the proposed LVRT control strategy is shown in Fig 5.

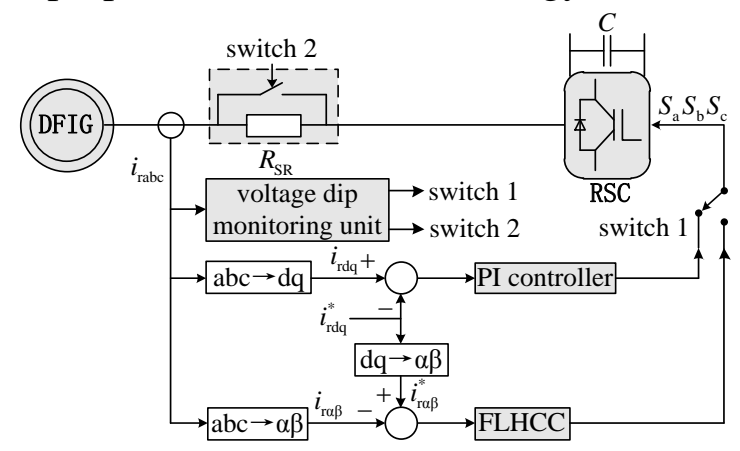

Fig.5 Schematic diagram of LVRT control strategy

Before the PCC voltage sags, the DFIG operates at the slip $s=-0.2$ and the power factor $\cos \varphi=0.9$. The PCC voltage drops at $t=0.1 \mathrm{~s}$, and the duration is $0.1 \mathrm{~s}$. In this paper, the deep dip of PCC voltage is studied, i.e., the PCC voltage dip degree coefficient $k=0.9$. For different PCC voltage dip types, the DFIG rotor current and the dc-link capacitor voltage are researched, and their dynamic waveforms are shown in the Fig.6. For comparative analysis, the rotor current and dc-link voltage waveforms under the conventional PI control strategy are also given in Fig.A1 of the appendix.
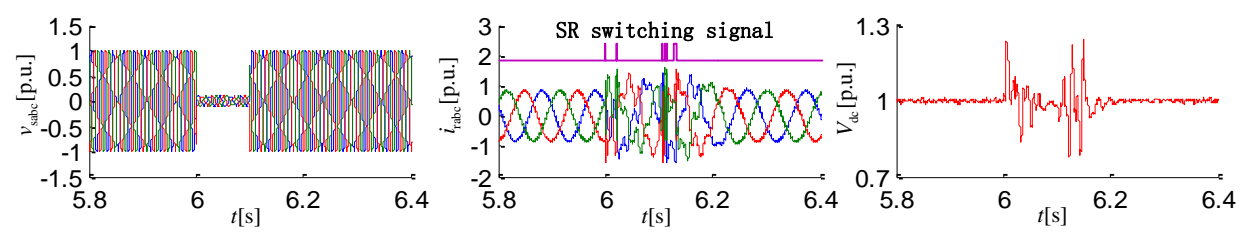

(a) symmetrical voltage dip


(b) phase b and c voltage dip 


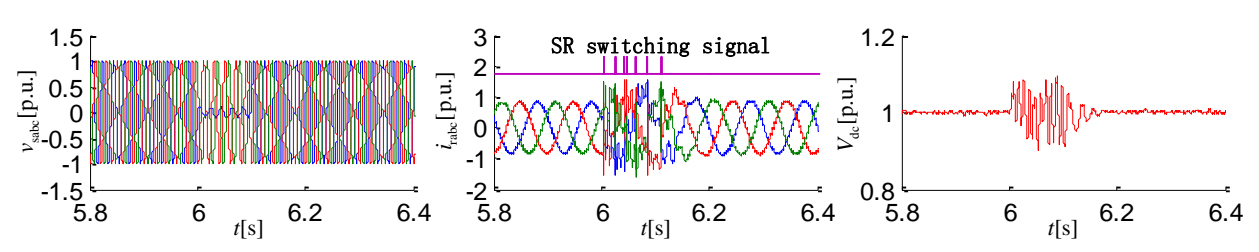

(c) phase a voltage dip

Fig.6 Dynamic waveforms of $i_{\mathrm{rabc}}$ and $V_{\mathrm{dc}}$

By comparing Fig.6 and Fig.A1, it can be seen that the LVRT strategy proposed in this paper improves the LVRT capability of DFIG to a certain extent. The detailed result comparison is shown in the Tab.3.

Tab.3 Result comparison

\begin{tabular}{c|c|c|c|c|c|c}
\hline \multirow{2}{*}{ fault types } & \multicolumn{3}{|c|}{ PI strategy } & \multicolumn{3}{c}{ proposed strategy } \\
\cline { 2 - 7 } & $I_{\text {rmax }}[$ p. u. $]$ & $V_{\text {dcmax }}[$ p.u. $]$ & SR trigger times & $I_{\text {rmax }}[$ [p. u. $]$ & $V_{\text {dcmax }}[$ [p. u. $]$ & SR trigger times \\
\hline symmetrical dip & 1.68 & 1.24 & 7 & 1.62 & 1.55 & 6 \\
\hline phase b and c dip & 1.67 & 1.13 & 5 & 1.65 & 1.16 & 15 \\
\hline phase a dip & 1.72 & 1.10 & 5 & 1.62 & 1.17 & 7 \\
\hline
\end{tabular}

\section{Conclusion}

The conventional PI control strategy has a poor transient control performance, to improve the LVRT ability of DFIG, a control strategy-based multi-controller switching is proposed in this paper. The proposed FLHCC further improves and optimize to the HCC introduced in [13] and [14]. In addition, according to the given rotor current and voltage limits $I_{r_{-} l i m}$, and $V_{r_{-} l i m}$, the resistance of series resistor is determined. Finally, the dynamic simulation of the proposed LVRT strategy is implemented, and the simulation results verify its feasibility. Meanwhile, LVRT capability of the proposed control strategy is compared with the conventional PI control strategy, and the results demonstrate the proposed LVRT control strategy can effectively restrain the rotor overcurrent and dc-link overvoltage and improves the LVRT capability of DFIG to a certain extent.

\section{Acknowledgement}

This work was supported in part by the Project of National Natural Science Foundation of China under Grant 46251277083.

\section{References}

[1] Y.K. He, P. Zhou, Overview of the low voltage ride-through technology for variable speed constant frequency doubly fed wind power generation systems (in Chinese), Transactions of China Electrotechnical Society, 2009, 24(9): 140-146.

[2] J. Morren, S.W.H. De haan, Ridethrough of wind turbines with doubly-Fed induction generator during a voltage dip. IEEE Trans. on Energy Conversion, 2005, 20(1): 435-441.

[3] X.G. Zhang, D.G. Xu, Research on control of DFIG with active crowbar under symmetry voltage fault condition (in Chinese), Electric Machines and Control, 2009, 13(1): 99-103.

[4] J. Lopez, E. Guba, P. Sanchis, et al, Ride through of wind turbines with doubly fed induction generator under symmetrical voltage dips, IEEE Trans. on Industrial Electronics, 2009, 56(10): 4246-4254.

[5] A.O. Ibrahim, T.H. Nguyen, D.C. Lee, et al, A fault ride-through technique of DFIG wind turbine systems using dynamic voltage restorers, IEEE Trans. on Energy Conversion, 2011, 26(3): 871-881. 
[6] P.S. Flannery, G. Venkataramanan, A fault tolerant doubly fed induction generator wind turbine using a parallel grid side rectifier and series grid side converter, IEEE Trans. on Power Electron, 2008, 23(3): 1126-1135.

[7] A. Causebrook, D.J. Atkinson, A.G. Jack, Fault ride-through of large wind farms using series dynamic braking resistors, IEEE Trans. on Power System, 2007, 22(3): 966-975.

[8] D.W. Xiang, R. Li, Control of a doubly fed induction generator in a wind turbine during grid fault ride-through, IEEE Trans. on Energy Conversion, 2006, 21(3): 652-662.

[9] J.B. Hu, D. Sun, Y.K. He, et al, Modeling and control of DFIG wind energy generation system under grid voltage dip (in Chinese), Automation of Electric Power Systems, 2006, 30(8): 21-26.

[10]J. Lopez, E. Guba, P. Sanchis, et al, Wind turbines based on doubly fed induction generator under asymmetrical voltage dips, IEEE Trans. on Energy Conversion, 2008, 23(1): 321-330.

[11]S.H. Gao, C.H. Zhang, D.S. Geng, et al, Control strategy of fault ride-through capability enhancement for doubly-fed wind generation (in Chinese), Power System Protection and Control, 2013, 41(5): 126-132.

[12]S.H. Gao, C.H. Zhang, D.S. Geng, et al, Control strategy of low voltage ride-through for double-fed wind generator (in Chinese), Proceedings of the CSU-EPSA, 2014, 26(8): 34-39.

[13]J. Zeng, Q.H. Diao, Y.X. Ni, et al. A novel current control method for active power filter based on optimal voltage vector (in Chinese), Automation of Electric Power Systems, 2000, 24(6): 25-31.

\section{Appendix}

The main parameters of DFIG are as follows:

Tab.A1 Main parameters of DFIG

\begin{tabular}{ll||ll}
\hline parameters & value & parameters & value \\
\hline rated power & $2[\mathrm{MW}]$ & stator leakage inductance & $0.105[\mathrm{p} . \mathrm{u}]$. \\
rated stator voltage & $690[\mathrm{~V}]$ & rotor resistance & $0.0055[\mathrm{p} . u]$. \\
]-ratio of stator to rotor & 0.63 & rotor leakage inductance & $0.1[\mathrm{p} . \mathrm{u}]$. \\
rated frequency & $50[\mathrm{~Hz}]$ & magnetizing inductance & $3.953[\mathrm{p} . \mathrm{u}]$. \\
stator resistance & $0.005[\mathrm{p} . \mathrm{u}]$. & pole pairs & 2 \\
\hline
\end{tabular}

The dynamic waveforms of $i_{\text {rabc }}$ and $V_{\mathrm{dc}}$ under conventional PI control strategy
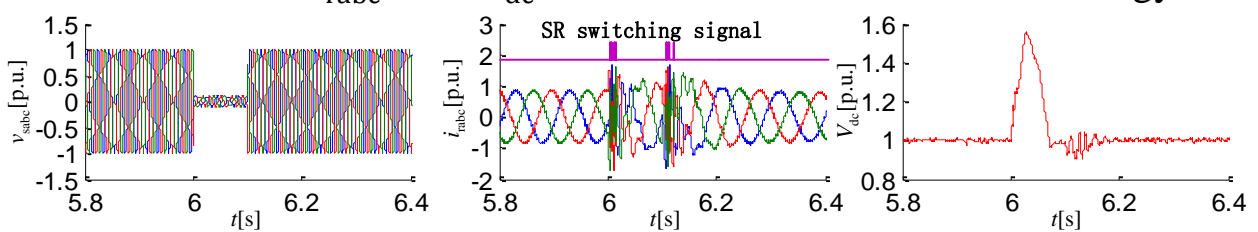

(a) symmetrical voltage dip
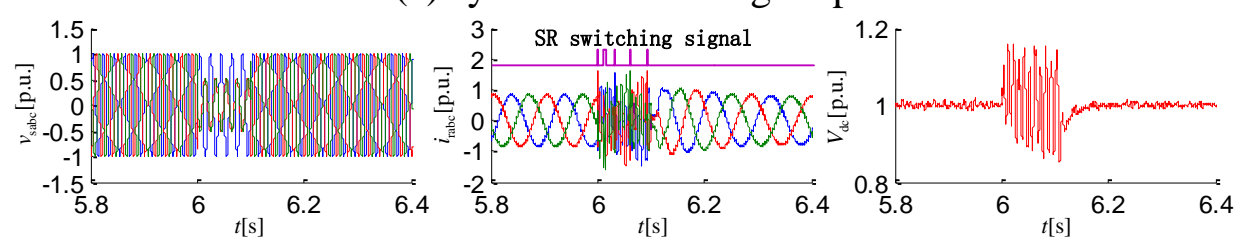

(b) phase b and c voltage dip
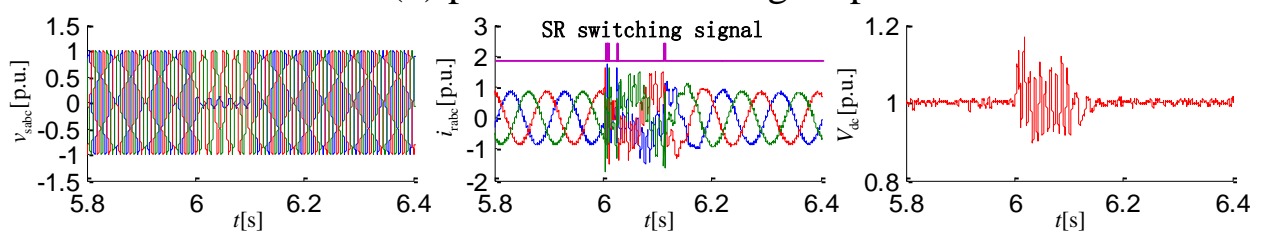

(c) phase a voltage dip

Fig.A1 Dynamic waveforms of $i_{\mathrm{rabc}}$ and $V_{\mathrm{dc}}$ 